\title{
Do the Infant Respiratory Distress Syndrome and Presumed Sepsis affect Thyroid Function in Preterm Newborns within the First 10 Days of Life?
}

\begin{abstract}
Objective: To investigated whether Preterm Infants (PI) who develop IRDS and/or sepsis in the first 10 days of life exhibit changes in thyroid function.

Method: Prospective, longitudinal cohort study included all PI admitted and who required NICU for more than 48 hours and remained hospitalized for 10 days or more, that were divided into four groups: 1. No IRDS orsepsis (CG); 2. With IRDS (IG); 3. With Presumed Sepsis (SG); and 4. With both IRDS and presumed sepsis (ISG). The odds that both TSH and T4 levels would be abnormal, the odds that TSH levels alone would be abnormal (with normal T4), and the odds that T4 concentrations would be abnormal (with normal TSH) at days 3 and 10 of life, as a function of Gestational Age (GA), birth weight 5-minute Apgar score, presence of IRDS, presence of early-onset sepsis, or presence of both IRDS and sepsis were estimated by stepwise backward regression analysis.
\end{abstract}

Results: Eighty-three PI (22 in CG, 25 in IG, 21 in SG, and 15 in ISG) were included in the study. The odds that TSH and free T4 concentrations would be abnormal on the day 3 of life in PI may be associated with GA and presumed sepsis, but not on the day 10 of life. GA, 5-minute Apgar score, and sepsis were factors capable of altering TSH concentrations on the day 3 of life, with a particular role of Apgar score, but not on the day 10 of life. Free T4 would be abnormal on day 3 and day 10 of life were influenced by GA.

Conclusion: PI who had a low 5-minute Apgar score and developed or are suspected to have developed neonatal sepsis, measurement of TSH and T4 concentrations should be postponed until after the day 10 of life, so as to prevent false-positive results of thyroid hormone assessment.

\section{Introduction}

It is well established that, in full-term newborns, levels of Thyroxine (T4) rise in the first 48 hours, rising up to values two to three times higher than those found in adults, before stabilizing and returning to the values measured in cord blood within five to six days [1,2]. However, in preterm neonates, the rise in $\mathrm{T} 4$ is not so significant and is related to immaturity levels of Thyroid-Stimulating Hormone (TSH) are proportional to the gestational age [1,2]. It is still controversial whether diseases that occur with greater frequency in preterm infants, such as the Infant Respiratory Distress Syndrome (IRDS, formerly known as hyaline membrane disease) and sepsis, hinder interpretation of thyroid function tests $[3,4]$. Thyroid function seems to be the predominant mode in which the body defends itself metabolically, through a reduction in energy expenditure [5]. Within this context, we investigated whether preterm infants who develop IRDS and/or sepsis in the first 10 days of life exhibit changes in thyroid function.

\section{Journal of \\ Pediatrics \& Child Care}

\author{
da Silveira Lopes Góes C* and Moraes Barbosa AD \\ Neonatologists, Maternal and Child Department, Fluminense \\ Federal University, Brazil \\ *Address for Correspondence: \\ Camila da Silveira Lopes Góes, Neonatologists, Maternal and Child \\ Department, Fluminense Federal University, Niterói, Rio de Janeiro, \\ Brazil; E-Mail: camilaneonatal@gmail.com (or) adutra@globo.com \\ Submission: 08 November, 2017 \\ Accepted: 08 December, 2017 \\ Published: 12 December, 2017 \\ Copyright: (๑) 2017 da Silveira Lopes Góes C, et al. This is an open \\ access article distributed under the Creative Commons Attribution \\ License, which permits unrestricted use, distribution, and reproduction in \\ any medium, provided the original work is properly cited.
}

\section{Method}

This prospective, longitudinal cohort study included all newborn infants admitted for care at the neonatal ICU of Hospital Universitário Antônio Pedro da Universidade Federal Fluminense, Niterói, Rio de Janeiro, Brazil, who required NICU care for more than 48 hours and remained hospitalized for 10 days or more between May 2013 and April 2016. An intentional non probability sampling strategy was used, whereby infants were enrolled systematically and consecutively.

We excluded all patients with congenital malformations and those whose guardians did not provide written informed consent for participation.

Gestational age (in weeks), birth weight (in grams), and 1-minute and 5-minute Apgar scores were obtained from the neonates' hospital records.

The preterm neonates enrolled in the study were divided into four groups: 1. No IRDS or sepsis. These formed the Control Group (CG); 2. Those diagnosed with IRDS (IG); 3. Those with presumed sepsis (SG); and 4. Those with both IRDS and Presumed Sepsis (ISG).

Gestational age was assessed by the new Ballard method. When this was not possible, it was based on the date of last menstrual period or on the findings of the most recent obstetric ultrasound, as recorded in the mother's medical record.

For diagnosis of IRDS, we considered chest X-ray findings and the individual and clinical evaluation of the patient regarding the need for supplemental oxygen and the presence of respiratory distress.

For diagnosis of presumed sepsis, we used the hematological scoring system of Rodwell [6]. In this system, the diagnosis of presumed neonatal sepsis is established by the presence of three or more of the following criteria in the peripheral blood: Leukocytosis $(>25,000)$ or Leukopenia $(<5,000)$; increase in immature neutrophils; Immature-to-Mature (I:M) neutrophil ratio > 0.3; Immature-toTotal (I:T) neutrophil ratio $>0.2$; platelet count less than or equal to $100.000 / \mathrm{mm}^{3}$; and presence of major degenerative changes in neutrophils. The presence of two or fewer criteria is considered negative for diagnosis, and is associated with a $99 \%$ likelihood of sepsis being absent. 
Citation: da Silveira Lopes Góes C* and Moraes Barbosa AD. Do the Infant Respiratory Distress Syndrome and Presumed Sepsis affect Thyroid Function in Preterm Newborns within the First 10 Days of Life?. J Pediatr Child Care. 2017;3(2): 03.

TSH and free T4 were measured in blood samples collected for routine testing on the day 3, day 10 of life. Serum free T4 and TSH were assayed by chemiluminescence in an Immulite 2000 system. The normal reference range was defined as $>4 \mathrm{micro} \mathrm{UI} / \mathrm{mL}$ for TSH and $<0.89 \mathrm{ng} / \mathrm{dL}$ for free T4 [7].

The Shapiro-Wilk test rejected the assumption of normality. As the sample was small and non-normally distributed, we used the Kruskal-Wallis test for comparison between medians of the variables of interest (gestational age, birth weight, and TSH and T4 at day 3 and day 10 of life).

The odds that both TSH and T4 levels would be abnormal, the odds that TSH levels alone would be abnormal (with normal T4), and the odds that T4 concentrations would be abnormal (with normal TSH) at day 3, day 10 of life, as a function of gestational age, birth weight, 5-minute Apgar score, presence of IRDS, presence of earlyonset sepsis, or presence of both IRDS and sepsis were estimated by stepwise backward regression analysis. Associations were considered statistically significant if $p<0.05$. All statistical analyses were carried out in MedCalc version 17.9.2 (MedCalc Software bvba, Ostend, Belgium; http://www.medcalc.org; 2017). The present study was approved by the Universidade Federal Fluminense Research Ethics Committee.

\section{Results}

The study sample comprised 83 premature newborns (22 in CG, 25 in IG, 21 in SG, and 15 in ISG).

Table 1 shows median gestational age (in weeks), birth weight (g), and T4 and TSH values on the day 3, day 10 of life in the study groups, compared using the Kruskal-Wallis test.

Table 1 Comparison of median gestational age, birth weight, and $\mathrm{TSH}(\mathrm{microUI} / \mathrm{mL})$, and free T4 (ng/dL) concentrations at age 3 and 10 days in the study groups.

As shown in Table 2, the odds that TSH and free T4 concentrations would be abnormal on the day 3 of life in preterm infants may be associated with gestational age and presence of sepsis.

The variables included in the model did not influence the odds that both TSH and free T4 levels would be abnormal on the day 10 of life.

Tables 3, 4, 5, and 6 show the results of logistic regression analysis to calculate the odds of TSH and free T4, separately, being abnormal in at day 3 and day 10 of life.

Table 3 shows that gestational age, 5-minute Apgar score, and sepsis were factors capable of altering TSH concentrations on the day 3 of life, with a particular role of Apgar score.

The variables included in the model did not influence the odds that TSH levels would be abnormal on the day 10 of life.

The odds that free T4 would be abnormal on day 3, day 10 of life were influenced by gestational age (Tables 4 and 5).

\section{Discussion}

Our results corroborate the findings of previous studies, which demonstrated an inversely proportional relationship between
Table 1: Comparison of median gestational age, birth weight, and TSH (microUl/ $\mathrm{mL}$ ), and free $\mathrm{T} 4(\mathrm{ng} / \mathrm{dL})$ concentrations at age 3 and 10 days in the study groups.

\begin{tabular}{|c|c|c|c|c|c|c|}
\hline & $\mathbf{C G}(\mathbf{n}=\mathbf{2 2})$ & $\mathbf{I S G} \mathbf{( n = 2 5 )}$ & $\mathbf{S G}(\mathbf{n = 2 1})$ & $\mathbf{I G} \mathbf{( n = 1 5 )}$ & Hcorr & $\mathbf{p}$ \\
\hline GA (wks) & 30 & 31 & 31 & 31 & 4.488 & 0.213 \\
\hline Weight (g) & 1,135 & 1,090 & 1,220 & 1,110 & 2.617 & 0.454 \\
\hline Apgar (5-min) & 8 & 9 & 9 & 8 & 0.302 & 0,960 \\
\hline TSH (day 3) & 3.59 & 3.75 & 4.52 & 6.35 & 4.573 & 0.206 \\
\hline TSH (day 10) & 4.88 & 3.94 & 3.67 & 4.23 & 1.825 & 0.61 \\
\hline Free T4 (day 3) & 1.37 & 1.46 & 1.46 & 1.55 & 5.268 & 0.153 \\
\hline $\begin{array}{c}\text { Free T4 (day } \\
\text { 10) }\end{array}$ & 1.37 & 1.43 & 1.53 & 1.53 & 7.093 & 0.067 \\
\hline
\end{tabular}

Table 2: Odds of abnormal TSH and/or free T4 levels at day 3 of life.

\begin{tabular}{|c|c|c|c|c|c|c|}
\hline Variable & $\boldsymbol{\beta}$ & Sp & \multicolumn{2}{|c|}{ Wald } & OR & 95\% CI \\
\hline GA & 0.45643 & 0.17092 & 7.1311 & 0.0076 & 1.5784 & 1.1291 to 2.2066 \\
\hline Apgar5min & 0.58945 & 0.24191 & 5.9371 & 0.0148 & 1.803 & 1.1222 to 2.8968 \\
\hline Sepsis & -1.87746 & 0.73287 & 6.5628 & 0.0104 & 0.153 & 0.0364 to 0.6434 \\
\hline Constant & -16.1845 & 5.69032 & 8.0896 & 0.0045 & & \\
\hline
\end{tabular}

Table 3: Odds of abnormal TSH levels at day 3 of life.

\begin{tabular}{|c|c|c|c|c|c|c|}
\hline Variable & $\boldsymbol{\beta}$ & Sp & Wald & $\mathbf{p}$ & OR & $\mathbf{9 5 \%} \mathbf{C l}$ \\
\hline GA & 0.356 & 0.16737 & 4.5239 & 0.0334 & 1.4276 & 1.0283 to 1.9819 \\
\hline Weight & -0.0066986 & 0.0023884 & 7.8661 & 0.005 & 0.9933 & 0.9887 to 0.9980 \\
\hline $\begin{array}{c}\text { Apgar } \\
5 \text { min }\end{array}$ & 1.72973 & 0.48303 & 12.8237 & 0.0003 & 5.6391 & $\begin{array}{c}2.1880 \text { to } \\
14.5337\end{array}$ \\
\hline Sepsis & -1.46473 & 0.62011 & 5.5792 & 0.0182 & 0.2311 & 0.0686 to 0.7793 \\
\hline Constant & -16.80614 & 4.85557 & 11.98 & 0.0005 & & \\
\hline
\end{tabular}

Table 4: Odds of abnormal free T4 levels at day 3 of life.

\begin{tabular}{|c|c|c|c|c|c|c|}
\hline Variable & $\boldsymbol{\beta}$ & Sp & Wald & $\mathbf{P}$ & OR & $\mathbf{9 5 \%} \mathbf{C l}$ \\
\hline GA & -1.06214 & 0.37033 & 8.2262 & 0.0041 & 0.3457 & 0.1673 to 0.7144 \\
\hline Constant & 28.76667 & 10.59416 & 7.373 & 0.0066 & & \\
\hline
\end{tabular}

Table 5: Odds of abnormal free T4 levels at day 10 of life.

\begin{tabular}{|c|c|c|c|c|c|c|}
\hline Variable & $\boldsymbol{\beta}$ & $\mathbf{S p}$ & Wald & $\mathbf{p}$ & OR & $\mathbf{9 5 \% \mathbf { C l }}$ \\
\hline GA & -0.73834 & 0.32301 & 5.2249 & 0.0223 & 0.4779 & $\begin{array}{c}0.2537 \text { to } \\
0.9001\end{array}$ \\
\hline Constant & 19.16679 & 9.37428 & 4.1804 & 0.0409 & & \\
\hline
\end{tabular}

Gestational Age (GA) and immaturity of the Hypothalamic-PituitaryThyroid (HPT) axis, hindering adaptation of thyroid function to the external environment in the first days of life $[1,2,8,9]$. In this setting, the production capacity and tissue response of this gland are also limited. After the first week of life, with rapid maturation of the HPT axis, GA seems to lose all influence over TSH concentrations. Another important finding that warrants special attention is the 5-minute Apgar score. Its association with asphyxia is well known and, based on our findings, this factor is associated with five fold odds of an abnormal TSH concentration on day 3 of life [10]. Thus, the 5-minute Apgar score is an important factor that may serve as a marker to help clinicians decide whether to measure TSH during this period. Another finding of this study was the duration of the influence of GA over free T4 concentrations. Unlike TSH, free thyroxine continues to be influenced beyond the first week of life, possibly because the glandular structure of the thyroid is unable to maintain adequate production of this hormone [9]. This led us to decide against measuring free $\mathrm{T} 4$ levels before the day 10 of life, when hormone production will be adequately established. 
Citation: da Silveira Lopes Góes C* and Moraes Barbosa AD. Do the Infant Respiratory Distress Syndrome and Presumed Sepsis affect Thyroid Function in Preterm Newborns within the First 10 Days of Life?. J Pediatr Child Care. 2017;3(2): 03.

As preterm infants have a higher prevalence of IRDS and/ or sepsis and it is known that transient hypothyroxinemia may occur in critically ill neonates, the association of these two diseases we investigated herein with abnormalities in thyroid hormone concentrations led us to assume that IRSD could influence TSH and free T4 concentrations in the first 10 days of life, and that the presence of early-onset sepsis could-through stress caused by the release of catecholamines, among other substances, as observed in experimental studies-intensify maturation of the HPT axis, which would serve indirectly as a factor capable of decreasing the time to adaptation to the external environment, thus shortening the duration of hypothyroxinemia during the first 10 days of life [11-15]. We were unable to determine conclusively whether the presence of IRSD is associated with abnormalities in thyroid hormone concentrations, as also observed by Tanaka et al. 2006 [3]. However, in septic preterm infants, postponing measurement of TSH and free T4 would help reduce the rate of false-positive and false-negative results in neonatal screening for congenital hypothyroidism, thus preventing confusion and misdiagnosis, particularly in preterm infants with permanent forms of this condition, in whom false-negative results in hypothyroidism screening may occur due to late elevation in TSH levels.

\section{Conclusion}

In preterm infants who had a low 5-minute Apgar score and developed or are suspected to have developed neonatal sepsis, measurement of TSH and T4 concentrations should be postponed until after the day 10 of life, so as to prevent false-positive results of thyroid hormone assessment.

\section{References}

1. Feingold SB, Brown RS (2010) Neonatal thyroid function. NeoReviews 11

2. Fisher DA, Nelson JC, Carlton El, Wilcox RB (2000) Maturation of human hypothalamic-pituitary-thyroid function and control. Thyroid 10: 229-234.
3. Tanaka K, Shimizu T, Hosaka A, Akifumi Tokita A, Shiga S, et al. (2007) Serum free T4 and thyroid stimulating hormone levels in preterm infants and relationship between these levels and respiratory distress syndrome. Pediatr Int 49: 447-451.

4. Luo B, Yu Z, Li Y (2017) Thyroid hormone disorders and sepsis. Biomed Mater Eng 28: S237-S241.

5. Bayarri VM, Palle SB, Chinesta SS, López AM, Izquierdo ES, et al (2001) Prevalencia y significaciónprognóstica del syndrome del enfermoeutiroideo en patologíacrítica. Revista Clínica Espanhola 201: 572-574.

6. Rodwell R, Leslie AL, Tudehope DI (1988) Early diagnosis of neonatal sepsis using a hematologic scoring system. J Pediatr 112: 761-777.

7. American academy of pediatrics; Thyroid Association; Lawson Wilkins Pediatric Endocrine Society. Foley T, Kaplowitz PB, Kaye Cl, Sundararajan S, Varma SK (2006) Update of newborn screening and therapy for congenital hypothyroidism. Pediatrics 117: 290-303.

8. Forhead AJ, Fowden AL (2014) Thyroid hormones in fetal growth and prepartum maturation. J Endocrinol 221: R87-R103.

9. Costeira MJ (2003) Alterações da funçãotireoideanosrecémnascidosprematuros. Acta Pediatr Port 34: 105-111.

10. Pereira DN, Procianoy RS (2001) Efeitos da asfixia perinatal sobre os hormônios tireoidianos. J Pediatr 77: 175-178.

11. Silva MH, Araujo MC, Diniz EM, Ceccon ME, Carvalho WB (2015) Nonthyroidal illnesses syndrome in full-term newborns with sepsis. Arch Endocrinol Metab 59: 528-534.

12. Golombek SG (2008) Nonthyroidal illness syndrome and euthyroid sick syndrome in intensive care patients. Semin Perinatol 32: 413-418.

13. Rodriguez-Perez A, Palos-Paz F, Kaptein E, Visser TJ, Dominguez-Gerpe L, et al. (2008) Identification of molecular mechanisms related to nonthyroidal illness syndrome in skeletal muscle and adipose tissue from patients with septic shock. Clin Endocrinol (Oxf) 68: 821-827.

14. Rakers F, Bischoff S, Schiffner R, Haase M, Rupprecht S, et al. (2015) Role of catecholamines in maternal-fetal stress transfer in sheep. Am J Obstet Gynecol 213: 684.e1-9.

15. Dembek KA, Timko KJ, Johnson LM, Hart KA, Barr BS, et al. (2017) Steroids, steroid precursors, and neuroactive steroids in critically ill equine neonates. Vet J 225: 42-49. 